\title{
Modeling the Formation Process Physical and Healthy Competence Future Atomic Specialists
}

\author{
Georgii Ilmushkin, Olga Parkhaeva, Ekaterina Kukhareva \\ Dimitrovgrad Engineering and Technology Institute, Nrnu Mephi, Ulyanovsk Region, Russia
}

\section{Email address:}

gera1946@yandex.ru (G. Ilmushkin), ovparkhayeva@mephi.ru (O. Parkhaeva), kuxareva@mail.ru (E. Kukhareva)

\section{To cite this article:}

Georgii Ilmushkin, Olga Parkhaeva, Ekaterina Kukhareva. Modeling the Formation Process Physical and Healthy Competence Future Atomic Specialists. Education Journal. Vol. 9, No. 2, 2020, pp. 37-42. doi: 10.11648/j.edu.20200902.11

Received: November 19, 2019; Accepted: December 26, 2019; Published: March 23, 2020

\begin{abstract}
The authors of this work formulated in their studies the content of the concept of physical fitness and health competence of future specialists in the nuclear industry as an integral characteristic of a person, reflecting the formation of recreational and health and rehabilitation competencies; competencies in the field of maintaining a healthy lifestyle; possession of means of independent, methodically competent use of methods of physical education and health promotion, in addition, its structural components are determined on the basis of a systematic approach. At the same time, the introduced definition is the starting point for the continuation of the further scientific search for an effective model for the formation of sports and fitness competence of future specialists in the nuclear industry. The presented study is devoted to the design and theoretical substantiation of the structural-functional model of the process of formation of fitness and fitness competence of these specialists. Moreover, models are a demonstrative tool for the functioning of a certain object (system), illustrating the basic norms and rules of its behavior. The methodological basis of the study was made up of pedagogical modeling, systemic, activity-based, interdisciplinary, integrative and competency-based approaches. The principles on the basis of which the formation of the studied competency is carried out are determined: systematic and systematic; professional orientation, developing and educating training, science and communication with practice; combination of individual and collective forms of learning, integrativity. A structural and functional model for the formation of physical fitness and health competence of future specialists in the nuclear industry has been developed and theoretically justified, including interdependent and interconnected blocks: target, theoretical, methodological, structural and functional, substantive-technological, resultant-criterion, correctional and managerial, as well as block pedagogical conditions, designed to ensure the effective formation of this competency.
\end{abstract}

Keywords: Modeling, Formation, Competence, Motor Activity, Principles, Tructure

\section{Introduction}

The state of health and physical self-improvement is of key importance in professional development among the most important areas of personal development, in particular, spiritual, professional and social activities. Thus, one of the pressing problems of higher education is the study of the health of students, ways to maintain and improve it in the course of educational activities. In this regard, the state recognizes the priority importance of strengthening the health and physical development of students.

However, as evidenced by numerous publications of scientists, the number of students with various kinds of deviations of morphofunctional and psychological order is growing every year. This circumstance is explained by environmental changes for the worse, unhealthy lifestyle, low level of sanitary and hygienic culture, insufficient physical activity and other factors. Excessive mental work leads to a decrease in the level of functioning of the body systems and physical activity of students in the process of growing up.

This problem is especially typical for universities that train specialists for the nuclear industry [14]. The problems of improving and strengthening the health of students have been studied by many researchers (such as V. A. Baronenko, F. L. Dolenko, I. A. Mamakina, B. A. Naumov, etc.). The search of new didactic means, methods, organization and planning processes fizkulturno-an improving orientation in the aspect of realization of competence model of training was carried out by A. E. Bolotin, G. A. Garanina, E. L., Panova etc.

Of course, in these conditions, the problem of improving 
and strengthening the state of health, as well as physical self-improvement in the process of training engineers for this industry, where modern science-intensive technological processes are widely used, requiring production personnel to maintain high stress resistance and the necessary psycho-emotional state to make adequate and timely decisions.

However, many of the issues in the context of the formation of physical culture and health competence of future specialists of the nuclear industry are investigated and require close study.

\section{Problem}

In modern conditions of development of nuclear industry in Russia, particularly updates-lysed forming to culture and health competence of future specialists of the industry due to the nature of their professional activities, primarily related to the extremely high degree of responsibility requiring special requirements for training, qualification, status of their health and emotional stability. This, in turn, requires the construction, theoretical justification and approbation of the structural and functional model of the formation of physical culture and health competence of future specialists in the industry, which is a problem of research.

\section{About the Question Under Study}

\subsection{General Information}

Modeling is a tool (method) of scientific knowledge, which has a relatively large historical epoch of its formation, and is a universal method of cognition of objective reality. The studied object of knowledge is replaced by a model for its study. That is, a specific object is specially created, through which the characteristic properties, regularities of the object of knowledge are established. Models seem to replace the studied objects and they are similar to some extent with them, but are not identical to them [10]. In the context of these arguments, the author believes: "to know an object means to model it" [12].

Or Yu Nu Petrov's research by this method understand as a means of studying the object of interest to us, in the process of which the object under consideration is replaced by a system [16]. Thus, V. V. Krayevsky believes that the model is a kind of structured system of elements, which allows to study specific aspects of the subject of study [9]. Or in the study [9] the model is perceived as an " analogue, a substitute for the subject under consideration." That is, the model is a system, the results of the study of this system are the basis for establishing new knowledge about another system.

Thus, the analysis of the above definitions of "model" and "modeling" is evidence that under the model is meant an imaginary system that defines the object of study, able to replace it, that is, modeling, in essence, is an instrument of scientific knowledge of objective reality in all its manifestations. This is the approach we follow in our research.

\subsection{Modeling in Pedagogical Research}

Modeling is widely used in the study of pedagogical processes, in the construction of educational systems, etc. Thereby enriched pedagogical research with new effective possibilities. In turn, pedagogical modeling is defined as a manifestation of the real pedagogical system, which is designed in a special way for its study in accordance with the goals and objectives of the study [9]. Thus it is an instrument of cognition of objective reality.

Modeling in pedagogical research was further developed in the works of G. M. Ilmushkin [4-6], N. V. Kuzmina, V. M. Nesterenko, N. N. Nikitina, E. L. Osorgin, M. A. Petukhov, V. A. Slastenin, N. F. Talyzinoy and others. Pedagogical modeling involves the identification of teachers-ical facts, and regularities at the level of observations, expert evaluations, a variety of experiments (stating, formative, etc.), resulting pedagogical insights and improvements conceptual study, identifying the common, private, and casual pedagogical factor. The modeling process also includes an adequate choice of theoretical and statistical methods and the construction of statistical regression models of the study, as well as the widespread use of multivariate statistical analysis.

From the above it follows that the pedagogical modeling of the competence in question will be successful only if it covers the system object of knowledge. The projected model is designed to ensure the effective formation of physical culture and health competence of future specialists of the nuclear industry and an objective assessment of the formation of its components.

\section{Purpose of Research}

The aim of the study: theoretical and methodological justification and design of structural and functional model of the process of formation of physical culture and health competence of future specialists of the nuclear industry in the conditions of training in a technical University, designed to ensure its effectiveness.

\section{Methods of Research}

The theoretical and methodological basis for designing a model for the formation of physical culture and health competence of future specialists of the nuclear industry are:

\subsection{Pedagogical Modeling}

Pedagogical modeling, which provides an opportunity to reveal the structural components of the studied pedagogical system, to establish links between them, to identify existing patterns, as well as to predict the further process of development of the considered pedagogical system. Pedagogical modeling, as modeling in the general scientific understanding, means pedagogical activity [11] aimed at establishing a new large - scale pedagogical information, as well as at improving the learning process; at the same time, its objects are intangible; the result is a pedagogical model, which 
is a developing object. According to the famous scientist, Yu. $\mathrm{K}$. Babansky, pedagogical modeling is the highest and special form of visualization and a means of ordering information [1].

The models established during the study of pedagogical phenomena and processes are designed to ensure the performance of such functions as information, prognostic and visually-illustrative. Determining the results of the system, we can compare them with the predicted. Such approach will allow to correct in due time the investigated pedagogical process that, as a result, will provide optimum functioning of the studied pedagogical system.

\subsection{System Approach}

A systematic approach to the formation of physical culture and health competence [17], providing a holistic analysis of pedagogical phenomena, as well as revealing the measuring instrument of the competence in question; structural analysis of the studied model allowed it to be studied from the point of view of the system, including integratively interacting blocks: target, theoretical and methodological, structural and functional, content-technological, complex pedagogical conditions, performance-criteria.

Thus, the system approach as a whole is a set of General scientific methodological principles that aim the researcher to identify the features of internal relationships between the elements of the system and the specifics of the relationship of the system with other surrounding system objects. The system approach in combination with the modeling method is particularly effective. We widely use a systematic approach to modeling the process of formation of physical culture and health competence.

Evidence of this choice is that it allows rethink essence of the studied competence from the point of view of system analysis, because it seems like the education system of the personality, thus the survey is filled and enriched the theoretical and methodological substantiation of the model of formation of competence with the system approach and analysis.

It is no coincidence that the system approach is widely implemented in modern scientific research. It provides for the following fundamental goal: to identify the structural components of the pedagogical object of research, to characterize their properties, features of functioning. Find out what factors significantly affect the existence and functioning of the object (system). To study how the structural components of the system are interdependent and interact.

The essential characteristic of this approach is studied in many experimental works (B. S. Kogan, I. T. Frolov, etc.), as well as in pedagogical developments (S. I. Arkhangelsky, S. Y. Batysheva, A. P. Belyaeva, T. D. Ilyina, G. M. Ilmushkin, F. F. Korolev, etc.). The system approach is essentially a universal method of scientific knowledge of reality. Such researchers as V. p. Bespalko [2], N. V. Kuzmina, Yu. g. Tatur [21] and others were actively engaged in the study of pedagogical systems.

For the first time the system approach was used in pedagogical researches by F. F. Korolev [8]. This approach provides a scientific basis for the construction of the system, its functioning, and its analysis taking into account many pedagogical factors. However, the realization comes that any system is part of a more comprehensive system.

\subsection{Interdisciplinary Approach}

Interdisciplinary approach to the formation of the considered competence, the implementation of which is aimed at the application of cognitive knowledge from different fields of science. This approach enriches each of the studied disciplines with new knowledge as a result of the interpenetration of the content of training and the use of training technologies at the intersection of different areas of knowledge.

\subsection{Activity Approach}

The activity approach is based on the conceptual theoretical positions Of L. S. Vygotsky, P. Ya. Galperin, A. N. Leontiev, TA-lyzina N. F., D. B. Elkonin, which determine the fundamental psychological laws of training and education, based on the laws of personality development.

The activity approach provides studying of physical culture and improving competence not only in aspect of its structural components, but also functional relations and interactions, proceeding from the fact that the projected model is directed on strengthening of health of trained by improving activity, providing a wide spectrum for cognitive activity, therefore this approach takes the leading place in model of physical culture and improving competence.

The dialectical unity of the theory and practice of training and education acts as a special methodology in the study of the problem of modeling the designated competence [13].

It should be noted that such methodological approaches as axiological, integrative and competential occupy a significant place in the study.

So, having studied methodological approaches of modeling of physical culture and health competence of future specialists of the nuclear industry, we will further focus on the construction of the designated pedagogical model.

\section{Research Result}

\subsection{Generalities}

Thus, the developed and theoretically grounded in structural-functional model of the process of forming to health-improvement competence of future specialists of the nuclear industry during the classes of physical culture and sports, and perform various movement exercises complexes in the training process, which is a system of interrelated and interdependent units: the target, theoretical and methodological, structural-functional, content-technological, productive and criterion, correction and management of complex of pedagogical conditions that enable a holistic, consistent and phased to reflect and identify in in the generalized form structure, properties, regularities, interrelations and features of the investigated process, to identify and implement existing interdisciplinary relations in the structure of the content of training engineers nuclear sector 
for optimum structuring and consistency and system of formation of the investigated competence taking into account modern tendencies of development in education.

\subsection{Target Block}

The basis of the target block is the goals and objectives of the functioning of the model. The purpose of the considered pedagogical model is the formation of physical culture and health competence of students in the process of training sessions in physical culture and sports. In accordance with the objectives, we have identified the following set of targets to facilitate:

Formation of motivation for physical activity among students of special medical group through the use of innovative means of training of a health-improving nature; encouraging students to engage in physical activity in order to strengthen the health required in a future profession related to the nuclear industry; - students ' awareness of the social importance of physical culture in their professional development; - mastering knowledge of scientific, biological and practical bases of physical development and observance of a healthy lifestyle, applied skills and skills of practical experience for creative use of physical culture and improving means for providing vital and professional target tasks:

In the process of solving the designated targets for the formation of physical culture and health competence of students and the practical implementation of the content of training in physical culture, teachers-mentors should carry out the educational process, based on certain principles [7].

Thus, we have identified the basic principles by which the formation of physical culture and health competence is carried out: system and systematic; the principle of professional orientation, developing and educating training, scientific and communication with practice; a combination of individual and collective forms of training, integrativity.

\subsection{The Principle of Developing and Educating Learning}

The principle of developing and educating learning in the hierarchy of principles is system-forming, in fact, determines their co-subordination, while all other principles perform an auxiliary function in this system of principles to achieve a strategic goal, in this particular case - the formation of physical culture and health competence [3].

This principle, as a system-forming, is mutually conditioned with the principle of fundamentality and professional orientation, when the system under study is associated with the professional training of future specialists. We rely on the principle of science in structuring the content of disciplines, and it is implemented on the basis of modern scientific ideas and theoretical knowledge [3].

\subsection{The Principle of Combining Individual and Collective Form of Training}

The principle of combination of individual and collective forms of education means the use of individual and collective forms of education and their combinations [3].

\subsection{Integration}

The integration associated with combining elements into a unified whole in the process of development is marked by increase in the volume of and interconnections between the elements of the new holistic education, and is characterized by self-organization and the emergence of new qualities and properties that are uncharacteristic of the original elements [18].

The problems of integrativity are devoted to the work of researchers A. P. Belyaeva, E. V. Bondarevskaya, V. P. Borisenko, E. N. Gusinsky, I. F. Isaeva, V. V. kraevskogo, V. M. Rozina, V. A. Slastenina, E. I. Shia-Nova, etc.

Of course, the principles introduced in the process of physical education of future specialists of the nuclear industry are manifested in interaction with each other.

\subsection{Competence Approach}

The competence approach in the physical development of future specialists of the nuclear industry, which has a significant impact on the content, as well as on the structure of the content of physical education, is of particular relevance. The majority of experts suggest using non-traditional methods and technologies of training in the process of realization of the content of training in physical culture in the conditions of ideology of competence model [21].

Recall that many researchers in the promotion of professional competence suggest the predominant use of technology assimilation of knowledge, mastering skills, while ensuring the development of the cognitive component [19, 20].

The formation of this competence is primarily determined by the content of physical education in accordance with state educational standards and the division of students into typological groups, taking into account the state of health. All this fills the training of future specialists of the nuclear industry with a new meaningful meaning, reflecting the whole complex of pedagogical conditions and means of training in their physical education.

\subsection{Structural and Functional Model of Formation Physical Culture and Health Competence of Future Specialists of the Nuclear Industry}

In table 1 the structural and functional model of the formation of physical culture and health competence of future specialists of the nuclear industry is presented.

Table 1. Model of the process of formation of physical culture and health competence of future specialists of the nuclear industry.

I. TARGET BLOCK

Purpose: formation of physical culture and health competence of students in the process of training sessions in physical culture and sports

Objectives: to promote the formation of motivation for physical activity of students of special medical group through the use of innovative means of teaching, improving character; to encourage students to physical activity to strengthen health necessary in their future profession associated with the nuclear industry; the awareness of the students the social importance of physical culture in their professional development; to acquire knowledge of 
scientific biological and practical basis of physical development and observance of a healthy lifestyle, applied skills and practical expertise to the creative use of fitness tools to provide vital and professional targets. II. THEORETICAL AND METHODOLOGICAL BLOCK Methodological approaches: system, activity, interdisciplinary, axiological, integrative, competence.

Principles: developing and educative learning; scientific and communication with practice; systematic and systematic; professional orientation; combination of individual and collective forms of learning; integrativity

\section{STRUCTURAL AND FUNCTIONAL UNIT}

Functional components: cognitive, developmental, educational, health and prognostic. Content components of physical culture and health competence: motivational-value, cognitive, activity and personal.

IV. CONTENT AND TECHNOLOGY BLOCK

1. Optimal structuring of the content of physical education, taking into account the division of students into typological groups for health.

2. Health technologies, technology of level differentiation of training, collective and group forms of occupations, etc.

V. COMPLEX OF PEDAGOGICAL CONDITIONS

1. Availability of the necessary educational and methodological support of the educational process in physical culture and the creation of an optimally structured content in accordance with state educational standards, taking into account the division of students into typological groups for health reasons;

2. Creation of the educational environment providing the professional orientation of training to physical education, and the motivational environment for physical culture and sports, and also maintaining a healthy lifestyle;

3. Development of criteria-evaluation apparatus for determining the formation of physical culture and health competence of students, which allows to monitor the dynamics of its formation productively; 4. Implementation of innovative technologies in the course of educational and training sessions on physical education in the process of gradual formation of the studied competence; 5 . Systematic professional development of the teaching staff in physical culture and sports. VI. PERFORMANCE-CRITERIA BLOCK

Criteria: motivational-value, cognitive, activity and personal. levels and their indicators adaptive base productive creative VII. CORRECTIONAL AND MANAGEMENT BLOCK Correction by technology Correction in content

At the same time, the content of teaching physical education is implemented by teachers in the course of joint activities with students through methodically competent use of various means of pedagogical communication.

So, the content of physical education is realized by means of technologies of teaching physical education, which form the basis of the content-technological block. At the same time, the content of education is optimized by dividing it into typological groups according to the state of health. The most effective is the use of technology level differentiation in physical education classes.

\subsection{Pedagogical Condition}

The complex of pedagogical conditions providing effective increment of investigated competence of future bachelors at all stages of training of physical culture is revealed:

1. Availability of the necessary educational and methodological support of the educational process in physical culture and the creation of an optimally structured content in accordance with state educational standards, taking into account the division of students into typological groups for health reasons;

2. Creation of the educational environment providing the professional orientation of training to physical education and the motivational environment for occupations by physical culture sports, and also maintaining a healthy lifestyle;

3. Development of criteria-evaluation apparatus for determining the formation of physical culture and health competence of students, which allows to monitor the dynamics of its formation productively;

4. Implementation of innovative technologies in the course of educational and training sessions in physical education in the process of gradual formation of the studied competence;

5. Systematic professional development of the teaching staff in physical culture and sports.

\subsection{Performance-criteria Block}

Considering the performance-criterion block of the proposed model, it should be noted that it contains criteria, levels (adaptive, basic, productive, creative) and their indicators of the formation of physical culture and health competence. Thus, the performance-criterion block is a diagnostic tool for monitoring the formation of physical culture and health competence of students at any stage of physical education.

\subsection{Correctional and Management Unit}

Correction and management unit is necessary to correct the process of formation of the considered competence in students. Such a need arises in the case when this process goes through an undesirable scenario. In this case, a certain correction of the control of this process is needed to direct it in the right direction. Thus, the formation of the studied competence of students is carried out step by step in accordance with the goal-setting determined by the tasks, initial provisions, that is, the principles. Previously, the content of physical education is optimally structured in accordance with state educational standards and implemented by productive pedagogical technologies.

\section{Summary}

The theoretical and methodological foundations for modeling the process of formation of the studied competence, including system, axiological, competence, activity, interdisciplinary, integrative and personal approaches, as well as the principles of system and systematicity, the relationship of science and practice, professional orientation, etc., are analyzed and substantiated.

The optimal structuring of the content of physical training of students was carried out in accordance with state educational standards on the basis of competence and inter-disciplinary approaches taking into account their physical condition and implemented by productive innovative means of pedagogical communication, including modern directions of health, adaptive, therapeutic, recreational, non-traditional and other techniques. 
The developed model of formation of physical culture and health competence of future specialists of the nuclear industry provides a high level of physical culture and health competence and effective management of this process through its pedagogical correction, which ultimately will ensure their successful promotion in social and professional activities.

The study does not exhaust all aspects of the problem of formation of physical culture and health competence of future specialists of the nuclear industry in the process of physical culture and sports. Further scientific research can be directed to the issues related to the application and development of new complexes of motor exercises, health, adaptive, therapeutic, recreational methods for students of special medical groups, including various compensatory motor and other exercises that ensure the functioning of vital systems of the body.

The preferred spelling of the word "acknowledgment" in America is without an "e" after the "g". Avoid the stilted expression, "One of us (R. B. G.) thanks..." Instead, try "R. B. G. thanks". Put sponsor acknowledgments in the unnum-bered footnote on the first page.

\section{References}

[1] Babanskii, Y. K. Optimization of the learning process: obediance-cal aspect [Text] / Yu. K. Babanskiy. - Yeah.: Pedagogy, 1977. $-250 \mathrm{p}$.

[2] Bespalko V. p. Pedagogy and progressive technologies of education [Text] / V. p. Bespalko. - Yeah.: Publishing house of the Institute of vocational education of the Ministry of education of Russia, 1995. - 336 p.

[3] Zagvyazinsky, V. I. Theory of learning: modern interpretation [Text]: studies. manual for students. no. studies'. institutions / V. I. Zagvyazinsky. - 5th ed., erased. - Yeah.: Publishing center "Academy", 2008. - 192 p.

[4] Ilmushkin, G. M. System modelling in the process of implementation of continuous multilevel training of specialists [Text]: monograph / G. M. Ilmushkin. - Moscow-Dimitrovgrad: publishing house ditudUISTU, 2005. $-354 \mathrm{p}$.

[5] Ilmushkin, G. M. System modeling and implementation of a single educational space in the process of continuous multi-level training of a specialist: on the example of small and medium-sized cities [Text]: dis.... doctor of pedagogy: 13.00 .08 / Ilmushkin Georgy Maksimovich. - Togliatti: Togliatti state University, 2002. -44 p.

[6] Ilmushkin, G. M. Forming to health-improvement competence of future specialists of the nuclear industry [Text] / G. M. Ilmushkin, O. V. Parhaeva // Theory and practice of physical culture and sports. - No. 963 (9). - Moscow, 2018. - Pp. 26-29.

[7] Kolesov, V. I. Continuity of physical education of young people in the holistic pedagogical process as the basis of a healthy lifestyle in modern society [Text]/ V. I. Kolesov, A. N. Smolonskaya, T. V. Sedletskaya, S. I. Smolonsky/ / Theory and practice of physical culture. - No. 3. - Moscow: Scientific and publishing center "Theory and practice of physical culture and sports", 2018. Pp. 100-101.

[8] Korolev, F. F. System approach and possibilities of its application in pedagogical researches [Text] / F. F. Korolev / / Soviet pedagogy. - Moscow: Enlightenment, 1970. - No. 9. Pp. 103-116.

[9] Kraevsky, V. V. Correlation of pedagogical science and practice [Text] / V. V. Kraevsky. - M., 1978. - 326 p.

[10] Kuzmina, N. V. Methods of system pedagogical education [Text]: textbook / ed. V. Kuzmina. - M.: Public education, 2002. - 208 p.

[11] Nikitina, N. N. Fundamentals of professional and pedagogical activity [Text]: studies. no. for students. environments'. prof. education / N. N. Nikitina, O. M. Zheleznyakova, M. A. Petukhov. - Moscow: Prowess, 2002. - 282 p.

[12] Novik, I. B. Questions of thinking style in natural science [Text] / I. B. Novik. - Moscow: Politizdat, 1975. - 144 p. nuclear University "MI-FI". - Moscow, 2018.

[13] Panova, E. L. Theoretical and methodological approaches to understanding health [Text] / E. L. Panova / / Theory and practice of physical culture. - No. 2.- Moscow: Scientific and publishing center "Theory and practice of physical culture and sports", 2018. Pp. 77-79.

[14] Parkhaeva, O. V. Fizkulturno-improving competence of future specialists of the nuclear industry [Text] / O. V. Parkhaeva, G. M. Il-Mushkin, A. A. Zharkova / / Scientific journal Englishmagazine "EuropeanProceedingsofSocialandBehaviouralsciences" (base WoS, UK), <url>. Conf. "Research Paradigms Transformation in Social Sciences" (Web of Science). - Irkutsk, 2018. Pp. 509-515.

[15] Pedagogy. Big modern encyclopedia [Text] / E. S. Rapatsevich. - Minsk: Modern word, 2005. - 720 p.

[16] Petrov, Yu. N. Organizational and pedagogical bases of management of continuous multilevel professional education [Text]: monograph / Yu. N. Petrov, S. M. Markova. - N. Novgorod: UGIE, 1999. - $172 \mathrm{p}$.

[17] Sadovnikov, E. S. Fizkulturno-improving activity in the context of the system approach [Text] / E. S. Sadovnikov / / Theory and practice of physical culture. - No. 9. - Moscow: Scientific and publishing center "Theory and practice of physical culture and sports", 2018. - P. 77.

[18] Selevko, G. K. Experience of system analysis of modern pedagogical systems [Text] / G. K. Selevko / / School technologies. - 1996. - No. 6. Pp. 5-43.

[19] Seregina, I. On socially significant aspects of communicative competence of Russian managers (to the problem statement) [Text] Vol. 1 / I. I. Seregina / / World of psychology. - 2000. No. 2. Pp. 77-84.

[20] Slastenin V. A. Basic tendencies of modernization of higher education [Text] / V. A. Slastenin / / Pedagogical education and science, manpo, 2004. - No. 1. Pp. 43-49.

[21] Tatur, Yu. G. Competence in the structure of the quality model of specialist training [Text] / Yu. G. Tatur / / Higher education today.-M.: Logos-2004. - No. 3. -Pp. 20-26. 